\title{
Heat of hydration of low clinker cements
}

\author{
Part II-determination of apparent activation energy and validity of the equivalent age \\ approach
}

\author{
Barbara Klemczak ${ }^{1}$ Maciej Batog ${ }^{1}$
}

Received: 26 January 2015/Accepted: 13 May 2015/Published online: 25 June 2015

(c) The Author(s) 2015. This article is published with open access at Springerlink.com

\begin{abstract}
Part I of this paper has reported the results of the experimental tests and discussed the influence of mineral additives on the hydration heat evolution. The purpose of the Part II of the paper is to study the validity of the equivalent age approach and determine the apparent activation energy of low clinker cements with mineral additives. The concept of the equivalent age method and Arrhenius formulation for the temperature sensitivity of the hydration reaction is briefly presented. The evolution of the apparent activation energy as well as its single values is determined on the basis of the tests results presented in Part I of the paper. The low clinker cements with 30,50 and $70 \%$ substitution ratio by ground granulated blast furnace slag or siliceous fly ash were studied. Finally, the results of semi-adiabatic and isothermal tests at different temperatures were compared to assess the validity of the equivalent age method with determined and recommended values of activation energy in relation to low clinker cements with mineral additives.
\end{abstract}

Keywords Low clinker cement · Slag · Fly ash ·

Temperature · Apparent activation energy $\cdot$ Equivalent age

\section{Introduction}

As it was described in Part I of this paper, the heat released in concrete during its hardening process produces various thermomechanical effects. Thus, the knowledge of the

Barbara Klemczak

Barbara.Klemczak@polsl.pl

Maciej Batog

Maciej.Batog@polsl.pl

1 Faculty of Civil Engineering, Silesian University of Technology, Akademicka 5, 44-100 Gliwice, Poland temperature sensitivity of the hydration process is crucial in many engineering tasks as accurate prediction of thermal gradients in massive concrete structures or assessment of early-age strength of concrete, which is influenced by curing temperature. For example, in modeling of exothermic temperature rise in massive concrete structures, the isothermal tests at $20^{\circ} \mathrm{C}$ are basically considered and they must be recalculated due to the developing temperature in each step of calculation [1-4]. The most common method applied for this purpose is an equivalent age approach, which is usually referred to Arrhenius concept. When the dependence of the Arrhenius rate concept is used, the temperature sensitivity of cementitious materials is described by the apparent activation energy and its value is required.

The activation energy can be determined by mechanical and calorimetric means. In mechanical means, the measurement is usually based on the development of compressive strength at different temperatures. It should be also noted that many proposals [5-9] for the activation energy formulation were determined from strength tests and that they were developed for the prediction of the early-age concrete strength. Nevertheless, many authors also recommended it for the prediction of the hydration development at temperatures other than the reference temperature. Different approaches in this field are proposed by authors [10-16], who derived this formulation on the basis of hydration heat development. Moreover, it is suggested that the activation energy determined from strength tests should not be used for predicting of hydration development. Poole et al. [14] also comment that isothermal calorimetry seems to be a better method to quantify the activation energy than the method based on the strength development. Nevertheless, the comparison of these two methods reported in [17] gives very similar values of the apparent activation energy. 
There is also disagreement in this field how to compute the activation energy from the isothermal tests. Such methods as a single linear approximation method, an incremental method and method of "rates" are described and summarized in [14, 17].

With respect to the factors influencing the activation energy value, experimental tests performed in this field showed that the activation energy is temperature-dependent and it is a function of the cement type and composition [13, 18]. The effect of a change in the water-cement ratio is unclear, because some authors have indicated that the activation energy is a function of the water-cement ratio, but it has been also shown that it does not have a consistent effect on the activation energy $[13,18]$.

The purpose of the Part II of the paper is to study the validity of the equivalent age approach and determine the apparent activation energy of low clinker cements with mineral additives. The results of isothermal tests at 20 and $50{ }^{\circ} \mathrm{C}$ have been the basis for the determination of the apparent activation energy. The method described as a "rate" method is applied. The calculation has been made for low clinker cements with 30, 50 and $70 \%$ substitution rate by ground granulated blast furnace slag or siliceous fly ash. Finally, the results of semi-adiabatic and isothermal tests at different temperatures were compared to assess the validity of the equivalent age method. In this comparative analysis, the determined single value of the apparent activation energy and recommended values of activation energy have been compared.

\section{Theoretical background}

As it has been mentioned in Part I of the paper, the hydration heat evolution determined in semi-adiabatic tests does not result in the same shape of the heat evolved versus time as it determined with the use of isothermal tests. It is because the retained heat causes the hydration to accelerate and the heat evolves at a much faster rate than in an isothermal test. The combined effect of temperature and time on the hydration heat development can be accounted with the use of equivalent age approach. In this approach, the curing time intervals at known temperatures are converted to equivalent time intervals at a selected reference temperature. Thus, the equivalent age represents the age at the reference curing temperature that would result in the same heat as would result from curing at other temperature. The reference temperature in European practice is generally taken as $20^{\circ} \mathrm{C}$. As explained by Carino [19], the equivalent age may be defined as follows

$t_{\mathrm{e}}=\int_{0}^{t} f(T) \mathrm{d} t \cong \sum_{i=1}^{n} f(T) \Delta t_{\mathrm{i}}$ where $f(T)$ can be called as a temperature function or as an affinity ratio [17], and it converts a curing time interval at any temperature to an equivalent time interval at the reference temperature. The temperature function $f(T)$ is defined as the quotient of the specific rate of reaction $k_{\mathrm{T}}$ at the given temperature $T$ and the specific rate of reaction $k_{\mathrm{T}_{\mathrm{o}}}$ at the reference temperature $T_{\mathrm{o}}$ :

$f(T)=\frac{k_{\mathrm{T}}}{k_{\mathrm{T}_{\mathrm{o}}}}$

The specific rate of reaction $k_{\mathrm{T}}$ can be defined as:

- a linear function of temperature proposed by Saul [20] $k_{\mathrm{T}}=\beta\left(T-T_{1}\right)$

where $\beta$ and $T_{1}$ are the coefficients.

- a function based on the Arrhenius equation [5]:

$k_{\mathrm{T}}=A \mathrm{e}^{-\mathrm{E}_{\mathrm{K}} / \mathrm{RT}}$

where $A$ is the parameter that is independent or varies little with temperature, $E_{\mathrm{K}}$ is the activation energy $\left(\mathrm{J} \mathrm{mol}^{-1}\right)$, and $R$ is the universal gas constant equal to $8.314 \mathrm{~J} \mathrm{~mol}^{-1} \mathrm{~K}^{-1}$.

- an exponential function [21]

$k_{\mathrm{T}}=C \mathrm{e}^{(\mathrm{BT})}$

where $C$ and $B$ are the coefficients.

Therefore, the temperature function $f(T)$ can be expressed in the following way:

$f(T)=\frac{k_{\mathrm{T}}}{k_{\mathrm{T}_{\mathrm{o}}}}=\frac{\left(T-T_{1}\right)}{\left(T_{\mathrm{o}}-T_{1}\right)}$ on the basis of Eq. (3)

$f(T)=\frac{k_{\mathrm{T}}}{k_{\mathrm{T}_{\mathrm{o}}}}=\frac{A \mathrm{e}^{-\mathrm{E}_{\mathrm{K}} / \mathrm{RT}}}{A \mathrm{e}^{-\mathrm{E}_{\mathrm{K}} / \mathrm{RT}_{\mathrm{o}}}}$

$=\mathrm{e}^{-\frac{\mathrm{E}_{\mathrm{K}}}{\mathrm{R}}\left(\frac{1}{\mathrm{~T}+273}-\frac{1}{\mathrm{~T}_{\mathrm{o}}+273}\right)}$ on the basis of Eq. (4)

$f(T)=\frac{k_{\mathrm{T}}}{k_{\mathrm{T}_{\mathrm{o}}}}=\frac{C \mathrm{e}^{\mathrm{BT}}}{C \mathrm{e}^{\mathrm{BT} \mathrm{o}}}=\mathrm{e}^{\mathrm{B}\left(\mathrm{T}-\mathrm{T}_{\mathrm{o}}\right)}$ on the basis of Eq. (5).

The linear function of temperature (Eq. 3) originally proposed by Saul with Bergstrom's suggestion [6, 22, 23] for $T_{1}=-10^{\circ} \mathrm{C}$ is often used because of its simplicity. However, it is known that this function describes correctly the effect of elevated temperatures only in the range of $5^{\circ}$ to $30^{\circ} \mathrm{C}[6,22,23]$. Such limitations do not pose the function of temperature based on the Arrhenius formulation (Eq. 4). There are also other proposals for the temperature function $f(T)$, which were basically derived on the basis of experimental tests [18]:

$f(T)=\frac{(T+10)(T+20)}{1200}$

In the Arrhenius equivalent age function, the activation energy that defines the temperature sensitivity of the 
hydration reaction has to be determined. One of the most commonly used definitions in Europe was proposed by Freiesleben Hansen and Pedersen [5]. This relationship is a function of the concrete temperature only:

$$
\begin{aligned}
& E_{\mathrm{K}}(T)=33,500 \quad \mathrm{~J} \mathrm{~mol}^{-1} \text { for } T \geq 20^{\circ} \mathrm{C} \\
& E_{\mathrm{K}}(T)=33,500+1470(20-T) \quad \mathrm{J} \mathrm{mol}^{-1} \text { for } T<20^{\circ} \mathrm{C}
\end{aligned}
$$

The similar formulation to the Freiesleben Hansen and Pedersen definition was proposed by Jonasson et al. [7]:

$E_{\mathrm{K}}(T)=44,066\left(\frac{30}{10+T}\right)^{0.45}$

The RILEM recommendations [6, 8] also define the activation energy as the function of temperature for Portland cement:

$E_{\mathrm{K}}(T)=33,536 \mathrm{~J} \mathrm{~mol}^{-1}$ for $T \geq 20^{\circ} \mathrm{C}$

$E_{\mathrm{K}}(T)=33,536+1455(20-T) \quad \mathrm{J} \mathrm{mol}^{-1}$ for $T<20^{\circ} \mathrm{C}$

For slag cements, the constant value $E_{\mathrm{K}}=$ $48,804 \mathrm{~J} \mathrm{~mol}^{-1}$ is recommended for whole range of temperature $[6,8]$. The above proposals define the activation energy irrespective of the cement type and mineral additions as fly ash, slag or silica fume. The activation energy formulation including such variables as cement composition, type and quantity of mineral additions and cement fineness but independent of curing temperature was developed by Schindler [13]:

$E_{\mathrm{K}}=22,100 \cdot f_{\mathrm{E}} \cdot d_{\mathrm{C}_{3} \mathrm{~A}}^{0.30} \cdot d_{\mathrm{C}_{4} \mathrm{AF}}^{0.25} \cdot$ Blaine $^{0.35}$

where $d_{\mathrm{C}_{3} \mathrm{~A}}$ is the mass ratio of $\mathrm{C}_{3} \mathrm{~A}$ in terms of the total cement content; $d_{\mathrm{C}_{4} \mathrm{AF}}$ is the mass ratio of $\mathrm{C}_{4} \mathrm{AF}$ in terms of the total cement content; Blaine is the specific surface of cement $\left(\mathrm{m}^{2} \mathrm{~kg}^{-1}\right)$ and $f_{\mathrm{E}}$ is defined as follows:

$f_{\mathrm{E}}=1-1.05 \cdot d_{\mathrm{FA}}\left(1-\frac{d_{\mathrm{FAaCaO}}}{0.40}\right)+0.40 d_{\mathrm{slag}}$

where $d_{\mathrm{FA}}, d_{\mathrm{FA}}, d_{\mathrm{FACaO}}$ are the mass ratio of fly ash, slag and $\mathrm{CaO}$ content of fly ash.

Figure 1 is a graphical comparison of different recommendations for the activation energy and the temperature function, which have been presented in Eqs. (6)-(14). The activation energy (Fig. 1a) calculated on the basis of the Schindler's approach is presented for the tested cements with different amounts of slag and fly ash. The temperature function with a reference temperature of $20^{\circ} \mathrm{C}$, computed on the basis of the Arrhenius function, and different activation energy values are plotted in Fig. 1b. For comparison, the proposal given in Eq. (9) which is independent of activation energy is also plotted.

Several observations can be made from Fig. 1. Very low values of the activation energy have been obtained from the

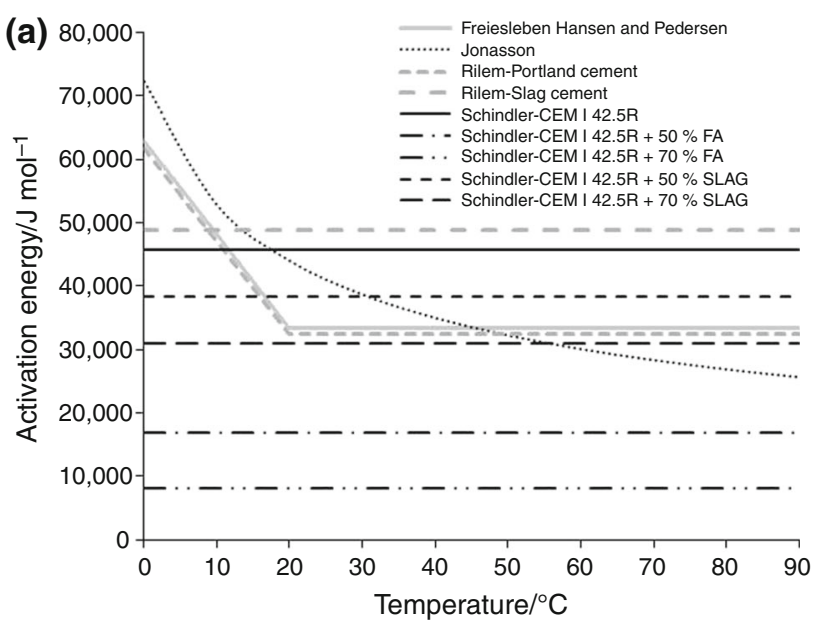

(b)

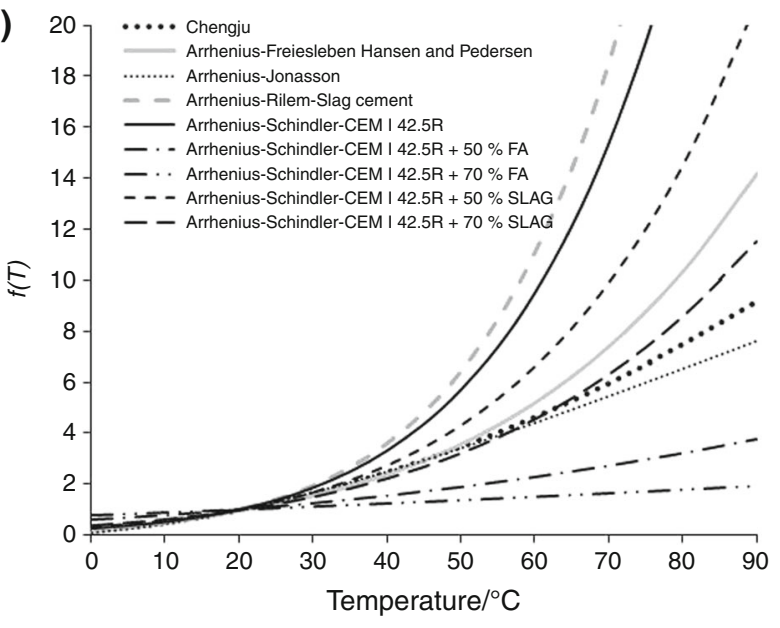

Fig. 1 Comparison of different activation energy values (a) and different temperature functions (b)

Schindler's approach for the cements with fly ash. The RILEM recommendations [6, 8] for Portland cement and the Freiesleben Hansen and Pedersen definition [5] give basically the same value of the activation energy. The nonlinear dependence of activation energy on temperature is visible in the proposal given by Jonasson et al. [7]. Obviously, the temperature function is equal to unity at the reference temperature of $20{ }^{\circ} \mathrm{C}$ regardless of the activation energy value and the method of its formulation. For the temperature lower than $20{ }^{\circ} \mathrm{C}$, all examined proposals result in the similar values of the temperature function, while for temperature greater than $40{ }^{\circ} \mathrm{C}$, discrepancies between the proposed temperature functions are significant. It can be also noticed that in the temperature range $0-60{ }^{\circ} \mathrm{C}$ the proposals given by Freiesleben Hansen and Pedersen [5], Jonasson [7] and Chengju [18] give essentially the same values. Analyzing the Schindler's proposal [13], very high dependence of temperature function on the cement composition is visible. 


\section{Determination of the apparent activation energy}

The "rate" method, described in [24, 25], has been used for the determination of the apparent activation energy. This method is similar to the procedure contained in ASTM C 1074 reported in [14] and concluded as relatively easy
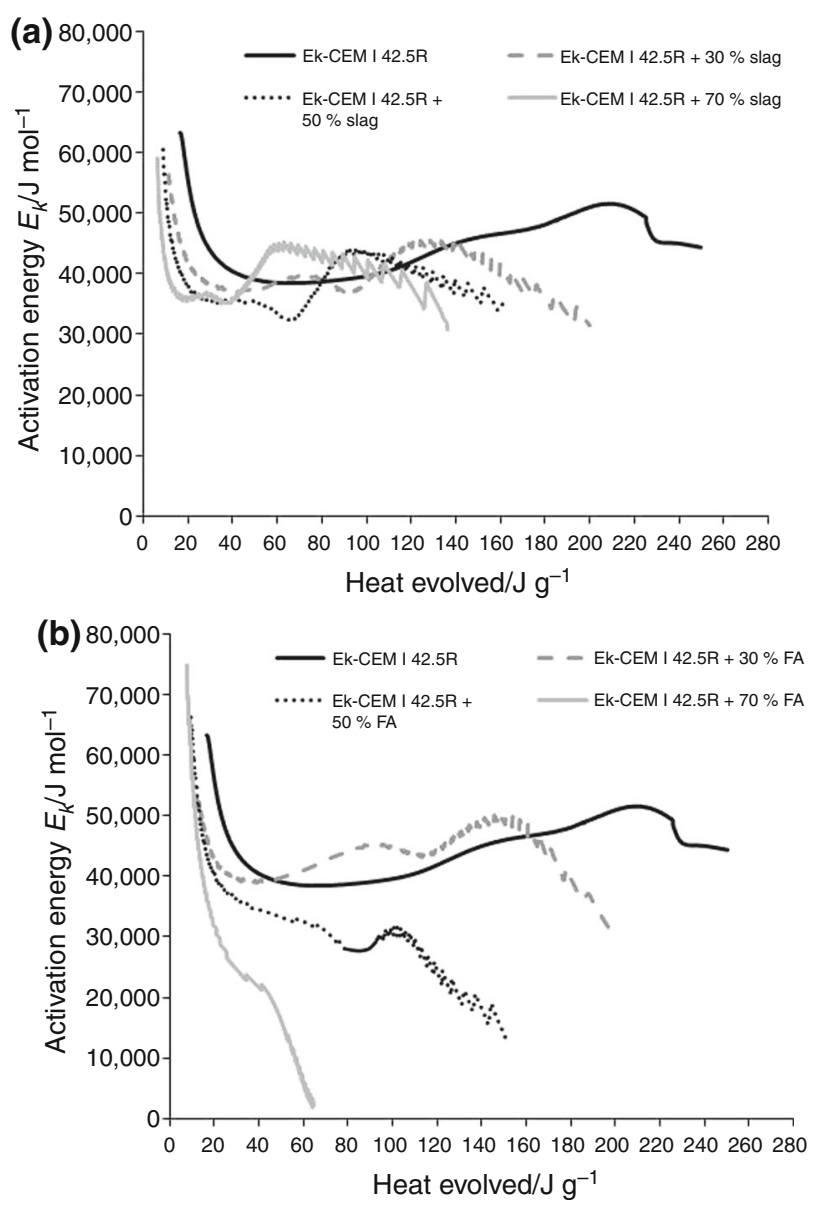

Fig. 2 Apparent activation energy of low clinker cement with slag (a) and fly ash (b) method as well as a best compromise between accuracy and practicality. For the known two curing temperatures, the apparent activation energy $E_{\mathrm{k}}$ can be calculated for each quantity of the released hydration heat $Q_{\mathrm{i}}$ as [25]:

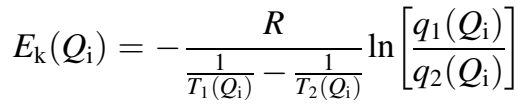

where $q_{1}\left(Q_{\mathrm{i}}\right)$ and $q_{2}\left(Q_{\mathrm{i}}\right)$ are heat evolution rates at two temperatures $T_{1}$ and $T_{2}$ recorded for the same amount of evolved heat $Q_{\mathrm{i}}$. As a result, the evolution of the apparent activation energy in the function of heat evolved is obtained. The results of isothermal tests at 20 and $50{ }^{\circ} \mathrm{C}$ reported in Part I of the paper have been used for the determination of the apparent activation energy evolution.

Figure 2 shows the results for the tested low clinker cement with ground granulated blast furnace slag (Fig. 2a) and siliceous fly ash (Fig. 2b). In both figures, the curves obtained for the ordinary Portland cement CEM I 42.5R are also plotted. In case of ordinary Portland cement, the values of apparent activation energy remain relatively constant in the range of heat between 40 and $140 \mathrm{~J} \mathrm{~g}^{-1}$. In case of $30 \%$ clinker replacement by slag or fly ash, the apparent activation energy curves are not as stable as in case of Portland cement, but it can be also regarded as almost stable in range 40 and $120 \mathrm{~J} \mathrm{~g}^{-1}$. There is no significant difference for the apparent activation energy between the binder with $30 \%$ of slag and Portland cement as well. In case of cements containing 50 and $70 \%$ of slag or fly ash, the results plotted in Fig. 2 show that the apparent activation energy strongly depends on the hydration heat released and thus on the degree of the chemical reaction. When 50 and $70 \%$ mass of cement are replaced by slag, short stable period is observed in the range of hydration heat $20-80 \mathrm{~J} \mathrm{~g}^{-1}$ (50\% of slag) and $20-50 \mathrm{~J} \mathrm{~g}^{-1}$ (70 \% of slag). Next, the apparent activation energy rises to the maximum value and then decreases, but the differences in the values are not very big. For 50 and $70 \%$ fly ash content in the binder, there is no stable period and in the whole

Table 1 Apparent activation energy values calculated from the experimental tests

\begin{tabular}{|c|c|c|c|c|c|c|c|}
\hline \multirow{2}{*}{$\begin{array}{l}\text { Calculation } \\
\text { method }\end{array}$} & \multicolumn{7}{|c|}{ Apparent activation energy, $\mathrm{J} \mathrm{mol}^{-1}$} \\
\hline & CEM I 42.5R & $\begin{array}{l}\text { CEM I } \\
42.5 \mathrm{R}+30 \% \\
\text { slag }\end{array}$ & $\begin{array}{l}\text { CEM I } \\
42.5 \mathrm{R}+50 \% \\
\text { slag }\end{array}$ & $\begin{array}{l}\text { CEM I } \\
42.5 \mathrm{R}+70 \% \\
\text { slag }\end{array}$ & $\begin{array}{l}\text { CEM I } \\
42.5 \mathrm{R}+30 \% \\
\text { FA }\end{array}$ & $\begin{array}{l}\text { CEM I } \\
42.5 \mathrm{R}+50 \% \\
\text { FA }\end{array}$ & $\begin{array}{l}\text { CEM I } \\
42.5 \mathrm{R}+70 \% \\
\text { FA }\end{array}$ \\
\hline \multicolumn{8}{|l|}{ Mean value } \\
\hline Period $^{\mathrm{a}}$ & $40-140 \mathrm{~J} \mathrm{~g}^{-1}$ & $40-120 \mathrm{~J} \mathrm{~g}^{-1}$ & $20-80 \mathrm{~J} \mathrm{~g}^{-1}$ & $20-50 \mathrm{~J} \mathrm{~g}^{-1}$ & $40-120 \mathrm{~J} \mathrm{~g}^{-1}$ & $20-60 \mathrm{~J} \mathrm{~g}^{-1 \mathrm{~b}}$ & $15-35 \mathrm{~J} \mathrm{~g}^{-1 \mathrm{~b}}$ \\
\hline Value & 40,153 & 38,647 & 35,179 & 36,552 & 43,985 & $34,865^{\mathrm{b}}$ & $29,285^{\mathrm{b}}$ \\
\hline Peak value & 44,137 & 39,158 & 33,800 & 38,267 & 44,670 & 34,800 & 35,950 \\
\hline
\end{tabular}

\footnotetext{
${ }^{a}$ Heat emission period with nearly stable value of the apparent activation energy

b Values with the best fit to the experimental results
} 
range of heat released the decreasing trend is visible. Thus, the high amount of fly ash in the binder substantially influences the activation energy behavior while in slag cement regardless of the clinker replacement rate $E_{\mathrm{k}}$ evolution can be regarded as almost stable.

In application of the equivalent age approach to the prediction of heat development in concrete structures curing at different temperatures, the single value of the apparent activation energy is convenient. Table 1 shows the mean values of the activation energy obtained in the stable region of the evolved heat $Q_{\mathrm{i}}$ for almost all tested binders. In case of 50 and $70 \%$ fly ash content in the binder, the values with the best fit to the experimental results have been found due to lack of stability period. Additionally, the values of the activation energy corresponding to the peak values of the heat evolution rate at $50{ }^{\circ} \mathrm{C}$ are specified. It can be noticed that in most cases these peak values are quite close to the mean values, curiously except for ordinary Portland cement and utterly intelligible for $70 \%$ fly ash content in the binder.

Once $E_{\mathrm{k}}$ has been calculated as a mean or a peak value, it can be used to predict the heat evolution rate with the use of converted form of Eq. (15). The predicted rate of the heat evolution has been compared with the measured rate to evaluate the accuracy of the determined constant values of the apparent activation energy for all tested materials. The results for ordinary Portland cement are shown in Fig. 3 and in Fig. $4 \mathrm{a}-\mathrm{c}$ for binders containing slag.

Figure 5 compares the measured and calculated heat evolution rate for binders with 30,50 and $70 \%$ of clinker replacement by fly ash. In case of high amount of fly ash (50 and $70 \%$ ) in the binder the calculated heat evolution rates reach the same peak values but the graphs are distinctly shifted. It should be pointed out that this is the best

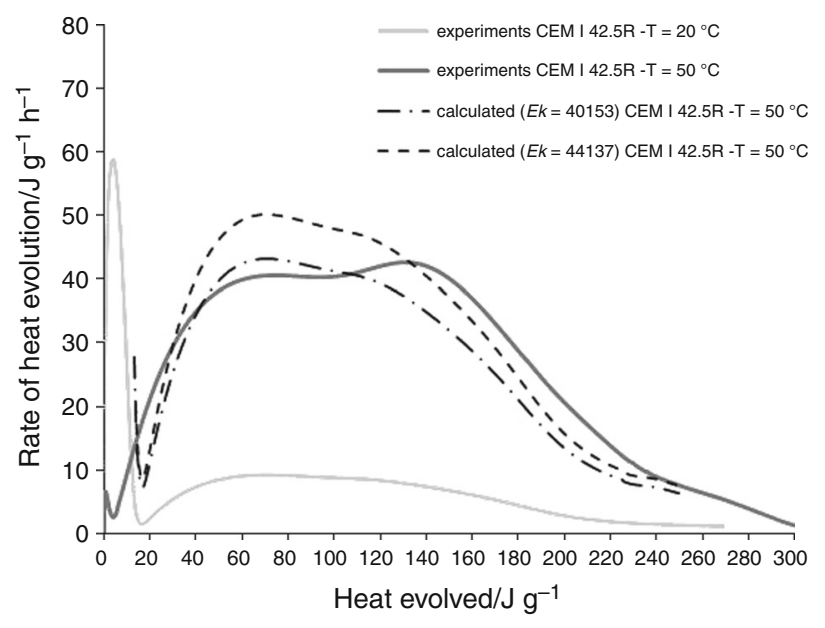

Fig. 3 Experimental and predicted rate of heat evolution - CEM I 42.5R possible fit of the measured and calculated rate evolution when the single value of the activation energy is assumed. In this case, the better compliance of measured and calculated heat evolution rate is obtained for the activation energy expressed as a function of the evolved heat $Q_{\mathrm{i}}$ :
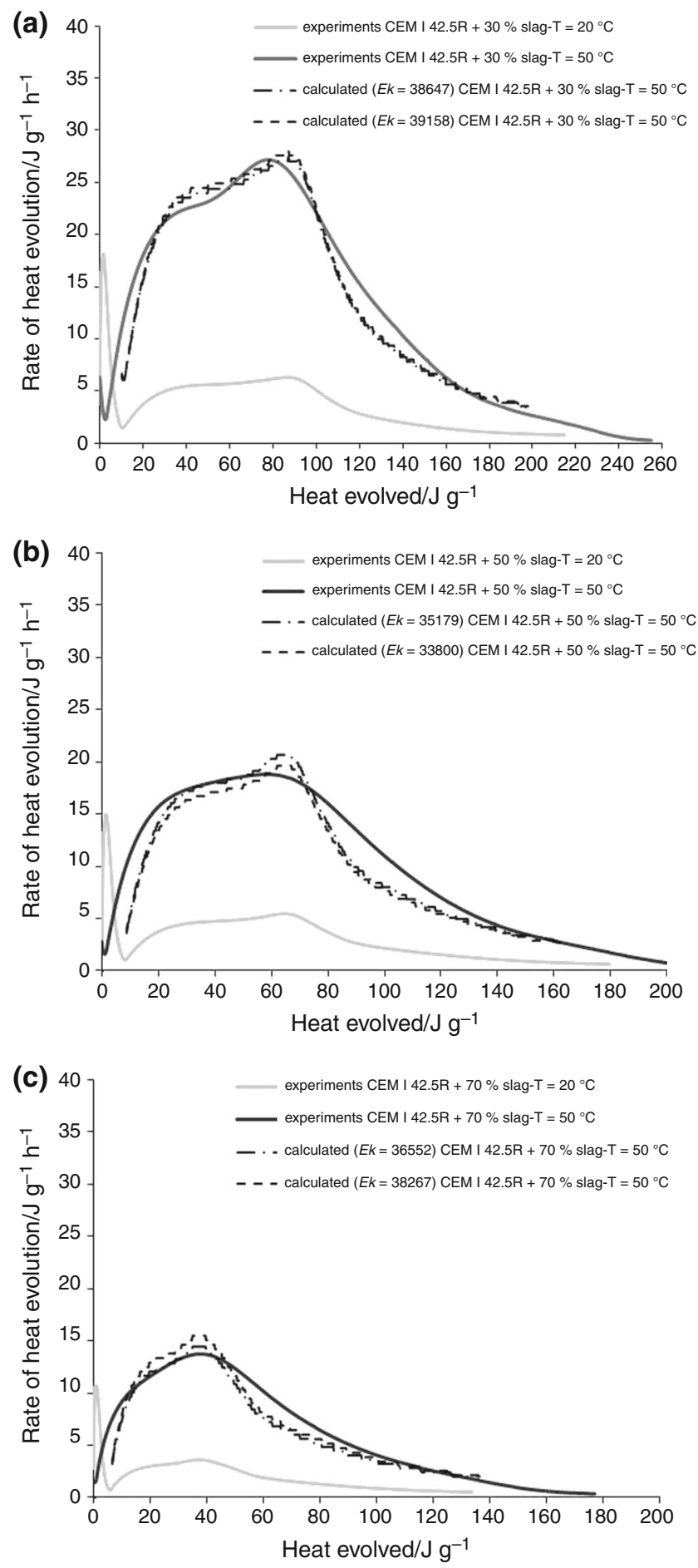

Fig. 4 Experimental and predicted rate of heat evolution-CEM I 42.5R with $30 \%$ of slag (a), CEM I 42.5R with $50 \%$ of slag (b), CEM I 42.5R with $70 \%$ of slag (c) 

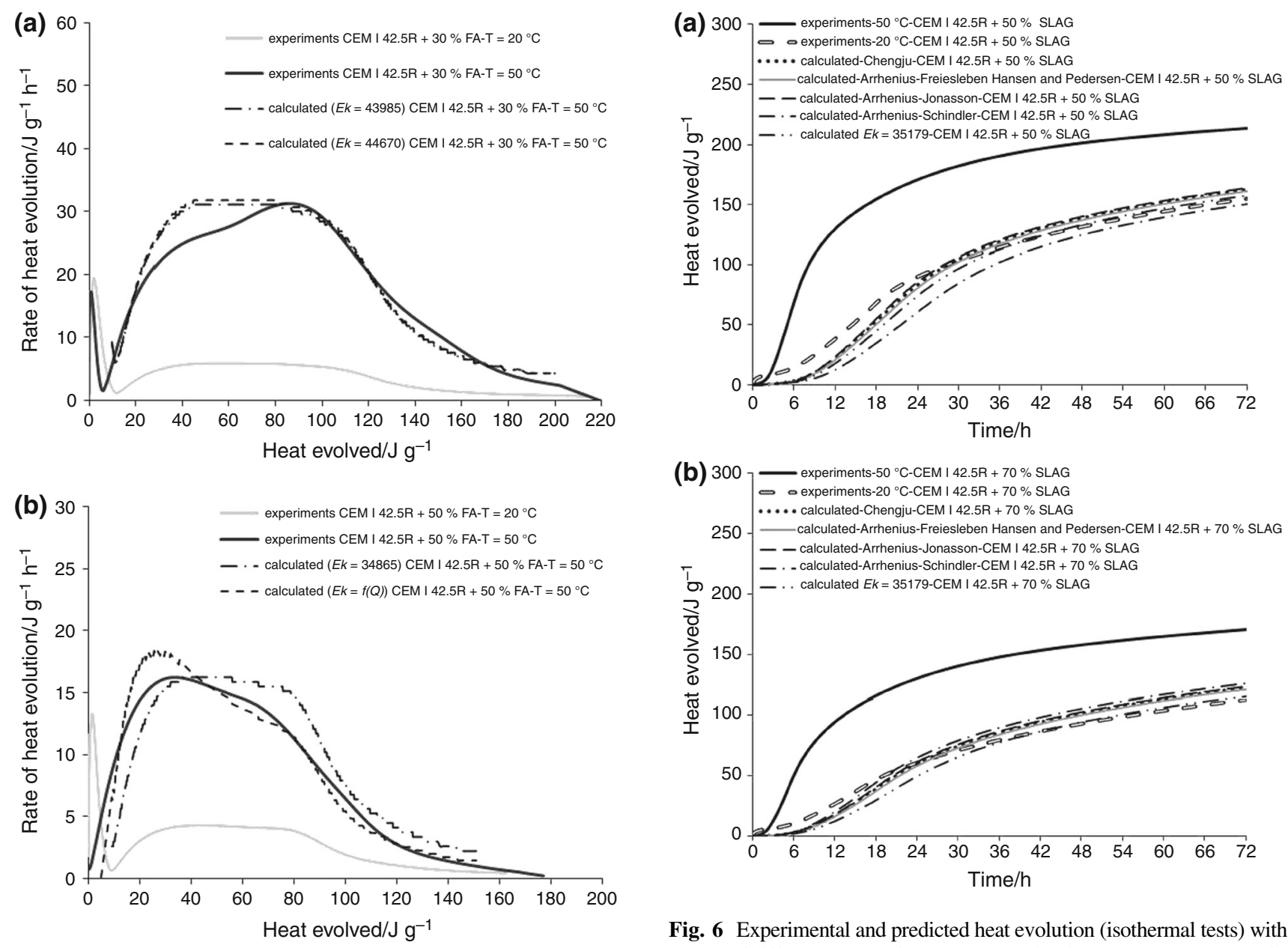

Fig. 6 Experimental and predicted heat evolution (isothermal tests) with the use of different values of the apparent activation energy - CEM I 42.5R with $50 \%$ of slag (a), CEM I 42.5R with $70 \%$ of slag (b)

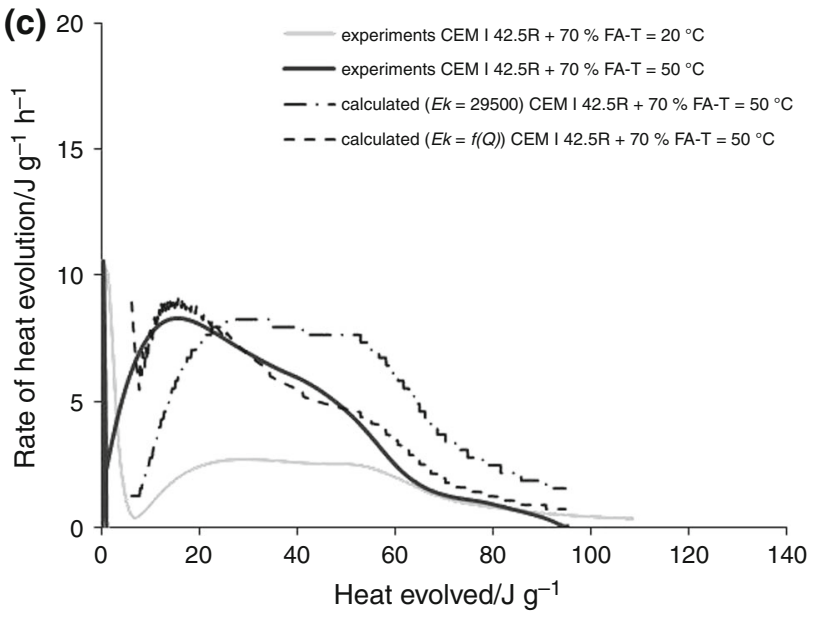

Fig. 5 Experimental and predicted rate of heat evolution-CEM I 42.5R with $30 \%$ of fly ash (a), CEM I 42.5R with $50 \%$ of fly ash (b), CEM I 42.5R with $70 \%$ of fly ash (c)

- for the $50 \%$ of clinker replacement by fly ash

$E_{\mathrm{k}}\left(Q_{\mathrm{i}}\right)=123490 Q_{\mathrm{i}}^{-0.337}$

- for the $70 \%$ of clinker replacement by fly ash

$E_{\mathrm{k}}\left(Q_{\mathrm{i}}\right)=320681 Q_{\mathrm{i}}^{-0.758}$

\section{Comparison of heat evolution tests results with the use of the equivalent age approach}

Therefore, it is possible to compare the results of the nonisothermal measurements (semi-adiabatic calorimetry) and the isothermal measurements made at two different temperatures with the use of the equivalent age approach. The recommended and deduced single values of the activation energy values have been introduced into the temperature function based on the Arrhenius equation, and the equivalent age has been determined. The temperature function proposed by Chengju [18] has also been evaluated. Finally, different values of the equivalent age have been obtained what allowed the conversion of results of the semi-adiabatic 

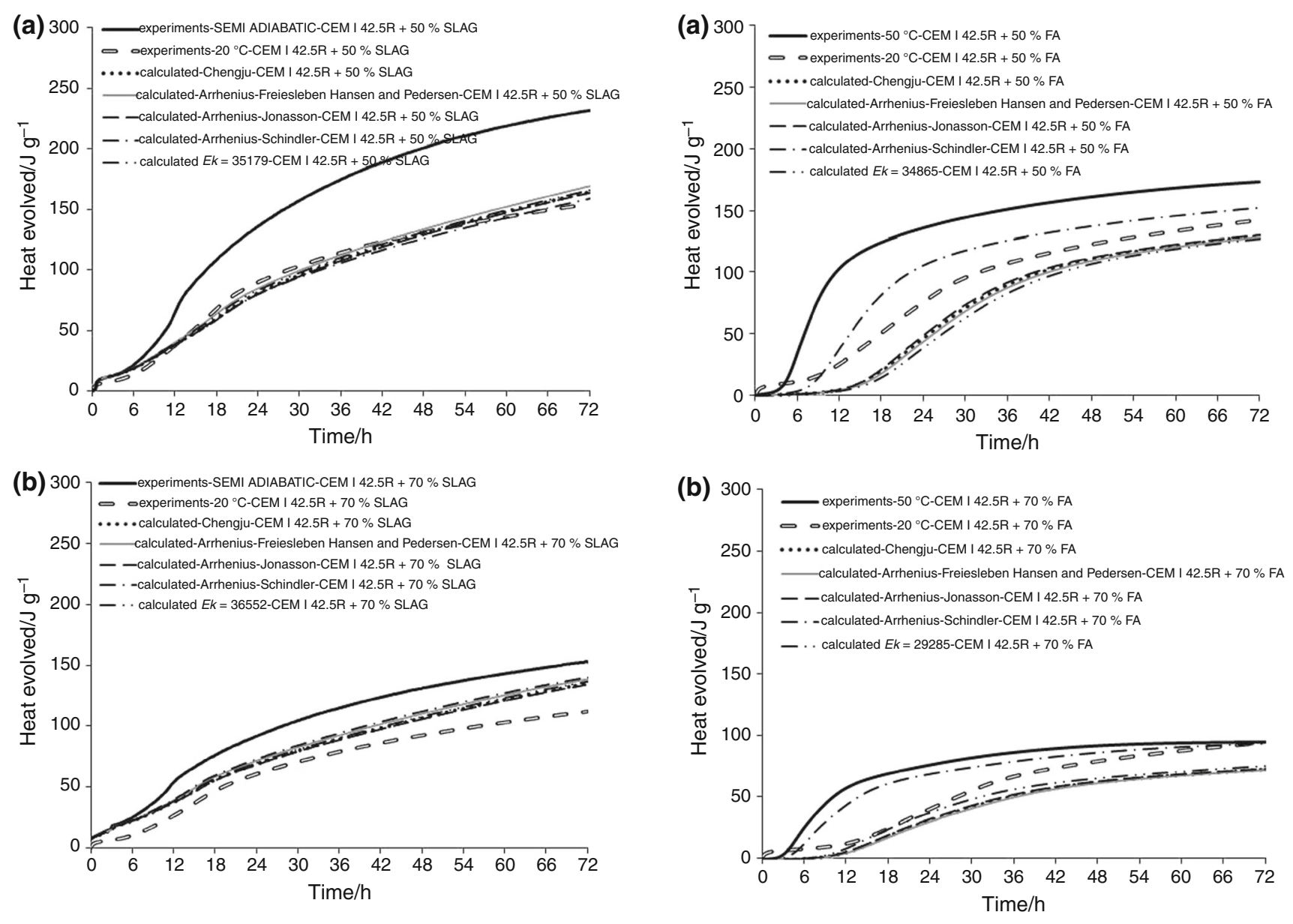

Fig. 7 Experimental and predicted heat evolution (semi-adiabatic tests) with the use of different values of the apparent activation energy-CEM I $42.5 \mathrm{R}$ with $50 \%$ of slag (a), CEM I 42.5R with $70 \%$ of slag (b)

and isothermal tests at $50{ }^{\circ} \mathrm{C}$ to the results obtained at isothermal tests at $20^{\circ} \mathrm{C}$. The results of such comparative analysis are shown in Figs. 6 and 7 for cement with 50 and $70 \%$ substitution rates of cement by siliceous ground granulated blast furnace slag and in Figs. 8 and 9 for cement with 50 and $70 \%$ substitution rates of cement by fly ash.

Graphical comparison of the discussed conversion of the tests results presented in Figs. 6-9 can be summarized as follows:

- The results of semi-adiabatic tests converted with the use of the equivalent age calculated on the basis of Arrhenius concept and the activation energy values proposed by Freiesleben Hansen and Pedersen [5] and Jonasson [7] fit well to the results of isothermal tests at $20^{\circ} \mathrm{C}$, despite the high content of mineral additions in cements. Similarly, good agreement is visible for Chengju's proposal [18], which skips the activation energy. When considering the Schindler's proposal for the activation energy, it can be noticed that for slag cement it gives good agreement but for cement with high amount of fly ash the activation energy is underestimated.

Fig. 8 Experimental and predicted heat evolution (isothermal tests) with the use of different values of the apparent activation energyCEM I 42.5R with $50 \%$ of fly ash (a), CEM I 42.5R with $70 \%$ of fly ash (b)

- The results of isothermal at $50{ }^{\circ} \mathrm{C}$ converted with the same methods as in case of semi-adiabatic tests showed quite good agreement for cement with slag; only for $70 \%$ substitution rate of cement by ground granulated blast furnace slag, the compliance is worse in case of the Schindler's proposal for the activation energy. For cement with fly ash, the large discrepancy in curves of heat evolution is visible, especially for cement with $50 \%$ content of fly ash. Interestingly, in case of the greater fly ash content in cement $(70 \%)$ the compatibility is better, except the Schindler approach.

- It is also interesting that in all cases there are no very substantial differences in calculated hydration heat evolution with the use of equivalent age concept despite the diversified values of activation energy assumed in the equivalent age concept. This would mean that the equivalent age concept is sensitive primarily to the temperature variations. At the same time, the best compliance is obtained for the values of the apparent activation energy derived on the basis of experimental tests. 

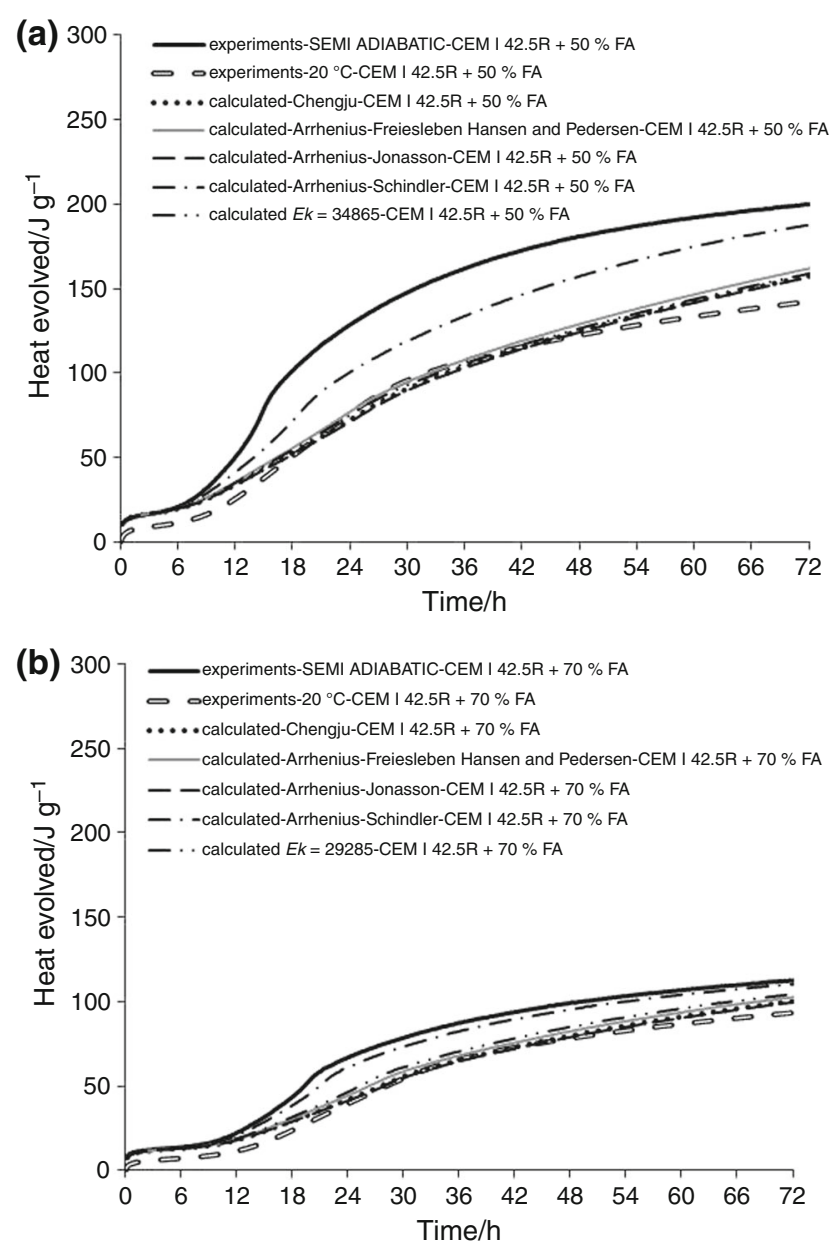

Fig. 9 Experimental and predicted heat evolution (semi-adiabatic tests) with the use of different values of the apparent activation energy-CEM I 42.5R with $50 \%$ of fly ash (a), CEM I 42.5R with $70 \%$ of fly ash (b)

\section{Conclusions}

The activation energy of a composite binder with three substitution rates of cement by ground granulated blast furnace slag or siliceous fly ash $(30,50$ and $70 \%)$ has been studied. The reference Portland cement has also been investigated. The single value of the apparent activation energy for each binder has been determined, and its correctness has been verified. Finally, the results of isothermal heat at different temperatures and semi-adiabatic heat were compared with use of equivalent age approach. The presented investigation on the activation energy and equivalent age concept can be summarized as follows:

- In case of ordinary Portland cement, the values of apparent activation energy remain substantially constant in the range of heat between $40 \mathrm{~J} \mathrm{~g}^{-1}$ and $140 \mathrm{~J} \mathrm{~g}^{-1}$. In case of $30 \%$ clinker replacement by slag or fly ash, the apparent activation energy curves are almost stable in a similar range $40 \mathrm{~J} \mathrm{~g}^{-1}$ and
$120 \mathrm{~J} \mathrm{~g}^{-1}$. In case of higher replacement rate (50 and $70 \%$ ) of clinker by slag, very short stable period is observed in the range of evolved heat $20-80 \mathrm{~J} \mathrm{~g}^{-1}$ (50\% of slag) and $20-50 \mathrm{~J} \mathrm{~g}^{-1}$ (70\% of slag). For 50 and $70 \%$ fly ash content in the binder, there is no stable period and in the whole range of heat released the decreasing trend of the apparent activation energy is observed.

- The determined single values of the apparent activation energy give good compliance of measured and calculated heat evolution rate in all binders except for binders containing high amount of fly ash (50 and $70 \%$ ). In this case, the proper peak value of heat evolution rate is achieved, but curves of heat evolution rate do not match. The good compliance for high amount of fly ash has been obtained for the activation energy expressed as a function of evolved heat.

- The comparison of isothermal and semi-adiabatic heat of hydration with the use of equivalent age concept and different values of activation energy showed quite good compliance between measured and calculated curves. What is interesting the differences in the hydration heat evolution are not significant despite assumed different values of the activation energy, except for the Schindler's proposal. Good agreement is also visible for the simple proposal [18], which skips the activation energy and accounts only temperature influence.

- Generally, better agreement between experiments and simulation has been obtained for cement with slag than for fly ash cement, especially for cement with $50 \%$ content of fly ash. Similarly, better agreement has been obtained in conversion of semi-adiabatic results to $20{ }^{\circ} \mathrm{C}$ than isothermal at $50{ }^{\circ} \mathrm{C}$ converted to $20{ }^{\circ} \mathrm{C}$. It can be probably explained by more complex effect of temperature on hydration process at higher temperature as $50{ }^{\circ} \mathrm{C}$ since in the semi-adiabatic tests the curing temperature did not exceed $43{ }^{\circ} \mathrm{C}$ in all reported studies.

Open Access This article is distributed under the terms of the Creative Commons Attribution 4.0 International License (http:// creativecommons.org/licenses/by/4.0/), which permits unrestricted use, distribution, and reproduction in any medium, provided you give appropriate credit to the original author(s) and the source, provide a link to the Creative Commons license, and indicate if changes were made.

\section{References}

1. Briffaut M, Benboudjema F, Torrenti JM, Nahas G. Effects of the early age thermal behaviour on long term damage risks in massive concrete structures. Eur J Environ Civ Eng. 2012;16(5): 589-605.

2. Benboudjema F, Torrenti JM. Early-age behaviour of concrete nuclear containments. Nucl Eng Des. 2008;238(10):2495-506. 
3. Briffaut M, Benboudjema F, Torrenti JM, Nahas G. Analysis of semi-adiabiatic tests for the prediction of early-age behavior of massive concrete structures. Cem Concr Compos. 2012;32:634-41.

4. Klemczak B, Knoppik-Wróbel A. Reinforced concrete tank walls and bridge abutments: early-age behaviour, analytic approaches and numerical models. Eng Struct. 2015;84:233-51.

5. FreiesInsen $P$, Pedersen EJ. Maturity computer for controlling curing and hardening of concrete. Nordisk Betong. 1977;1(19):21-5.

6. Rilem Technical Committee 42-CEA: properties of set concrete at early ages-state-of-the-art. Rep. Mater Struct. 1981;14, 411-33.

7. Jonasson JE, Groth P, Hedlund H. Modelling of temperature and moisture field in concrete to study early age movements as a basis for stress analysis. In: Proceedings of the international RILEM symposium on thermal cracking in concrete at early ages. London; 1995. p. 45-52.

8. RILEM Technical Committee 119-TCE. Adiabatic and semiadiabatic calorimetry to determine the temperature increase in concrete due to hydration heat of cement. In: R. Springenschmid, editor, E \& FN Spon. RILEM Report 15, prevention of thermal cracking in concrete at early ages, London; 1998. p. 315-30.

9. Zhang J, Cusson D, Monteiro P, Harvey J. New perspectives on maturity method and approach for high performance concrete applications. Cem Concr Res. 2008;38:1438-46.

10. Zakoutsky J, Tydlitat V, Cerny R. Effect of temperature on the early-stage hydration characteristics of Portland cement: a largevolume calorimetric study. Constr Build Mater. 2012;36:969-76.

11. D'Aloia L, Chanvillard G. Determining the "apparent' activation energy of concrete Ea-numerical simulations of the heat of hydration of cement. Cem Concr Res. 2002;32:1277-89.

12. Bentz DP. Activation energies of high-volume fly ash ternary blends: hydration and setting. Cem Concr Compos. 2014;53: 214-23.

13. Schindler AK, Folliard KJ. Heat of hydration models for cementitious materials. ACI Mater J. 2005;102(1):24-33.
14. Poole JL, Riding KA, Folliard KJ, Juenger MCG, Schindler AK. Methods for calculating activation energy for Portland cement. ACI Mater J. 2007;104(1):202-311.

15. Terzić A, Obradović N, Andrić L, Stojanović J, Pavlović V. Investigation of thermally induced processes in corundum refractory concretes with addition of fly ash. J Therm Anal Calorim. 2015;119:1339-52.

16. Han F, Zhang Z, Wang D, Yan P. Hydration kinetics of composite binder containing slag at different temperatures. J Therm Anal Calorim. 2015. doi:10.1007/s10973-015-4631-z.

17. Wirquin E, Broda M, Duthoit B. Determination of the apparent activation energy of one concrete by calorimetric and mechanical means influence of a superplasticizer. Cem Concr Res. 2002;32: 1207-13.

18. Chengju G. Maturity of concrete: method for predicting earlystage strength. ACI Mater J. 1989;86(4):341-53.

19. Carino NJ, Tank RC. Maturity functions for concretes made with various cements and admixtures. ACI Mater J. 1992;89(2): 188-96.

20. Saul AGA. Principles underlying the steam curing of concrete at atmospheric pressure. Mag Concr Res. 1951;2(6):127-40.

21. Carino NJ. Maturity functions for concrete. In: Proceedings RILEM international conference on concrete at early ages, vol. 1. 1982. p. $123-8$.

22. Bergstrom SG. Curing temperature, age and strength of concrete. Mag Concr Res. 1953;5(14):61-6.

23. Rilem TC. 119-TCE: avoidance of thermal cracking in concrete at early ages. Mater Struct. 1997;30:451-64.

24. Kada-Benameur H, Wirquin E, Duthoit B. Determination of apparent activation energy of concrete by isothermal calorimetry. Cem Concr Res. 2000;30:301-5.

25. Wirquin E, Broda M, Duthoit B. Conception of an isothermal calorimeter for concrete-determination of the apparent activation energy. Mater Struct. 2002;35:389-94. 